\title{
Clinical Relevance of Official Anatomical Terminology: The Significance of Using Synonyms
}

\author{
Relevancia Clínica de la Terminología Anatómica Oficial: La Importancia de Usar Sinónimos
}

Biljana Srdic Galic ${ }^{1}$; Sinisa S. Babovic ${ }^{1}$; Snezana Vukadinovic ${ }^{2}$ \& Goran Strkalj ${ }^{3}$

GALIC, B. S.; BABOVIC, S. S.; VUKADINOVIC, S. \& STRKALJ, G. Clinical relevance of official anatomical terminology: The significance of using synonyms. Int. J. Morphol., 36(4):1168-1174, 2018.

SUMMARY: Terminologia Anatomica is a unique collection of technical terms that enable communication in anatomy and medicine across the world. However, current anatomical terminology also contains some internal inconsistencies and discrepancies in regard to clinical terminology. Thus, a number of terms are not logically related to the names of similar anatomical entities, or the names of corresponding physiological and pathological conditions. Moreover, during clinical practice many anatomical terms have commonly been replaced by new, clinical idioms. These terminological discrepancies represent an impediment to learning and teaching in medical and health professions programs. In this paper it is proposed that the relevant synonyms should be introduced into Terminologia Anatomica in the same way as currently the case for the kidney (ren/nephros) and uterine tube (tuba uterina/salpinx). This change would significantly reduce inconsistencies in nomenclature and make anatomical terminology more logical, easier to understand and memorize. Further more, it would better align anatomy with other branches of medicine and medical education.

KEY WORDS: Anatomical nomenclature; Anatomical terminology; Gross anatomy education; Medical education; Synonyms.

\section{INTRODUCTION}

Throughout history, the discipline of anatomy has provided the educational foundation for all medical and health professions, since a sound knowledge of structure and function of the human body is prerequisite for safe and efficient clinical practice. Similarly, anatomical terminology, as complex and difficult as the discipline of anatomy itself, provides the basis for effective communication in all medical fields. A global agreement has been reached on the composition and usage of anatomical nomenclature. Terminologia Anatomica (TA) has been the result of a concerted effort by anatomists to produce a nomenclature for their discipline.

From a student's standpoint two things are very important: to understand the meaning of anatomical terms in order to avoid short-term and mechanical memorization, and to provide future understanding of the physiology, pathology and clinical subjects. Gest et al. (2009) succinctly articulated the essential attributes of the effective anatomical terminology when they stated that nomenclature has to be "simple, logical and consistent".
Smith et al. (2007) also showed that understanding etymology helps in learning anatomy to a large extent. However, some internal inconsistencies in TA would seem to impede this comprehension. An example is the names of some homologous structures which stem from different roots (e.g., diaphragma and $n$. phrenicus, and lingua and $n$. hypoglossus). On the other hand, clinical language has numerous terms not included in the official anatomical terminology, adding yet further and unnecessary difficulty to the learning process. Across many medical universities and faculties, after their preclinical studies, students begin their clinical work facing many new terms for different disorders, diseases, conditions, diagnostic and therapeutic procedures that cannot be brought into relation with previously learned names of corresponding anatomical structures (e.g. vesica biliaris and cholecystitis, or palpebra and blepharitis). As Hirsch (2011) noted in this respect: "as soon as our students begin their clinical clerkship, they will shift to the terms used by their clinical instructors, and that will become their permanent language". The reason of that confusion is using terms with roots from

\footnotetext{
${ }^{1}$ Department of Anatomy, Faculty of Medicine, University of Novi Sad, Novi Sad, Serbia.

${ }^{2}$ Department of History, Faculty of Philosophy, University of Novi Sad, Novi Sad, Serbia.

${ }^{3}$ Department of Chiropractic, Faculty of Science and Engineering, Macquarie University, Sydney, Australia.
} 
different languages. On several places $T A$ proposes two or more alternative terms to name the same structure but there are still some terms that could be supplemented by corresponding synonyms that will help understanding clinical language.

The aim of this review is to indicate the necessity of usage the synonyms in order to make anatomical language understandable to clinicians and to maintain logical continuity in learning during basic and specialized studies.

Synonyms in the Terminologia Anatomica. There are several instances in $T A$ where more than one term is listed to denote a single anatomical structure. This arrangement assists in understanding and better connecting relevant anatomic structures. For example, the anatomical terminology contains two names for kidney - ren and nephros. Thereby, nephros is used more often in clinical conditions (e.g. in glomerulonephritis, nephrolithiasis or nephrectomia), whereas the term ren is applied to the construction of other anatomical terms denoting structures related to the kidney (e.g. $a$. and v. renalis, fascia renalis). Considering the synchronal usage of these terms in anatomy and in the clinic, it would seem appropriate to include both in the official terminology. Similarly, listing the synonym for soft palate velum palatinum next to the preferred palatum molle would help in understanding the names of the two muscles of the soft palate $-m$. levator veli palatini and $m$. tensor veli palatini. Names of functional disorders of the hypophysis (hypopituitarismus, hyperpituitarismus) and names of the glial cells of the posterior lobe of hypophysis (pituicytes) are logically derived from the synonym of the hypophysis glandula pituitaria, which is also reasonably given as the alternative term in $T A$.

Simultaneous usage of the terms orchis $(o \rho \chi \imath \varsigma)$ and testis, as well as tuba uterina and salpinx $(\sigma \alpha \lambda \pi \imath \gamma \xi)$, is valid from the clinical standpoint; corresponding Greek-derived terms are more often used in clinical designations such as orchitis, anorchia, or salpingitis. Furthermore, the term salpinx is the root for the name of another anatomical structure - mesosalpinx, which is listed in the official terminology.

Terminologia Anatomica (and also new Terminologia Neuroanatomica) gives three options for the lower part of the brainstem: myelencephalon, medulla oblongata and bulbus which makes for easier understanding of other anatomical terms such as sulcus bulbopontinus or tractus bulboreticulospinalis, as well as clinical terms, e.g. bulbar palsy, corticobulbar tract, or myelography (Federative International Programme on Anatomical Terminologies, 2017).
Another example of the use of alternative terms in $T A$ is the synonym for the vertebral articular process zygapophysis, which provides a logical transition to the term articulatio zygapophysialis. Both the terms pudendum femininum and vulva are given in TA and, as such, assist in understanding the meaning of corresponding structures such as $n$. pudendus or canalis pudendalis, as well as associated clinical terms, e.g vulvitis or vulvovaginitis.

Potential new synonyms for the Terminologia Anatomica. In addition to the existing, a number of new synonyms could be introduced in the anatomical terminology to facilitate the understanding of other anatomical and clinical terms. There are numerous examples that highlight the differences between anatomical and clinical terminology when referring to the same structure. Linguistically, the main reason for this inconsistency is the fact that terms have their roots from words belonging to different languages. It appears that this occurs most commonly in ophthalmology, a medical specialty which utilizes mainly Greek-derived terms: the term ophthalmology itself derives from the Greek term ophthalmos $(o \varphi v \alpha \lambda \mu o \varsigma)$, rather than the Latin oculus; the clinical terms relating to the eyelids, e.g. blepharitis ( $\beta \lambda \varepsilon \phi \alpha \rho i \tau \iota \varsigma)$ and blepharoplastica $(\beta \lambda \varepsilon \phi \alpha \rho \sigma \pi \lambda \alpha \sigma \tau \imath \kappa \eta i)$ are derived from the word blepharon $(\beta \lambda \varepsilon \phi \alpha \rho o v)$, instead of the official anatomical term palpebra; inflammation of the lacrimal gland - dacriocystitis ( $\delta \alpha \kappa \rho v o \kappa v \sigma \tau \imath \tau \iota \varsigma)$ and cornea - keratitis ( $\kappa \varepsilon \rho \alpha \tau i \tau \iota \varsigma)$ originate from the Greek words - dacriocystis ( $\delta \alpha \kappa \rho v о \kappa i \sigma \tau \iota \varsigma)$ for lacrimal gland,

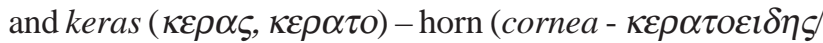
keratoeides), rather than from glandula lacrimalis and cornea, respectively; the synonym for the vascular tunic of the eye (tunica vasculosa) - uvea, which is unknown to official anatomical terminology, is used in the term which refers to the inflammation of iris, ciliary body (corpus ciliare) and choroid (choroidea) - uveitis. Previous versions of anatomical terminology (International Anatomical Nomenclature Committee, 1989) contained the term tractus uvealis, which seems more appropriate within the clinical setting. Inflammation of the iris and ciliary body iridocyclitis also contains a Greek term for corpus ciliare

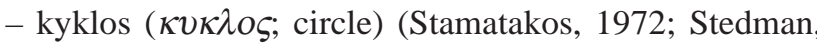
2005). Terms phacotomy, aphakia or phacocystitis are also derived from the Greek word phacos ( $\phi \alpha \kappa o ́ \varsigma)$ instead from

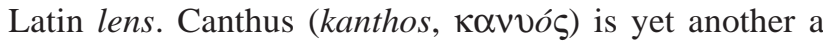
Greek term for the angle of the eye (angulus oculi or commissura palpebrarum in TA) that is clinically recognizable in terms like epicanthus and telecanthus.

Other medical specialties similarly feature terminological inconsistencies: the name otorhinolaryngology contains two terms that are unknown to the official terminology - otos and rhinos. The terms 
rhinitis and rhinoplastica are derived from the Greek term for nose - rhinos ( nasus. Additionaly, term rhinos is recognizable in the neuroanatomical terms referring to the position of olfactory structures - entorhinal area or rhinal sulcus. Instead of auris, the word ous (ov, ov, gen. $\omega \tau$ ó $\varsigma$ ) is used in the construction of the names otitis, otorrhea, otorrhagia, or otalgia. The official anatomical term glandula parotidea is logically constructed according to the gland's positional relationship with the auricle of the ear. Terms myringitis and myringoplastica don't associate on the name of the involved structure - eardrum (membrana tympanica) because they are derived from the term myringa (Stamatakos; Mosby's Medical Dictionary, 2013).

On a broader level, the chapter on General Terms in the TA should contain the synonym for cartilage - chondros ( $\chi \delta$ ó $\delta \rho \circ \varsigma$ ), which would facilitate the understanding of names of other anatomical structures such as artt. interchondrales, artt. costochondrales, regio hypochondriaca, and also several clinical conditions, e.g. achondroplasia, chondromalacia and chondrocyte (Panourias et al., 2011). The same chapter should also include terms such as viscera or splanchna $(\sigma \pi \lambda a ́ \gamma \chi v \alpha)$ that explain names like pleura visceralis, peritoneum viscerale, or nn. splanchnici.

The idiom spondylos $(\sigma \pi \delta v \delta v \lambda o \varsigma)$ is more often used in clinical practice than the official anatomical term vertebra in terms such as spondylosis or spondyloarthrosis (Panourias et al., 2011). The alternative term for columna vertebralis - spina dorsi - has its basis in medulla spinalis ("core of the spine"), nn. spinales, dura mater spinalis or spinal anesthesia. Panourias et al. (2011), also point to the alternative name notiaios myelos ( $v \omega \tau \imath \alpha i ́ s \mu v \varepsilon \lambda o ́ \varsigma)$ which is used in the terms notochorda, notalgia, myelomeningocela. The root myelos ( $\mu v \varepsilon \lambda o s)$ is contained in the term myelencephalon, which is given in TA with names medulla oblongata and bulbus. Hieron osteon (ícrón $o \sigma \tau \varepsilon o v$ ) is the old Greek term for sacrum ("sacred" or "holy" bone) and is used in terms describing the shape of sacrum - dolichohieric or platyhieric.

The word pneumonia ( $\pi v \varepsilon v \mu o v i \alpha)$ has its root in the Greek name for the lungs - pneumon $(\pi \nu v \mu \omega v)$, while $T A$ only contains the term pulmo. If the synonym phren would be listed next to the official term diaphragm students would easily understand terms such as $n$. phrenicus, recessus phrenicomediastinalis, a. phrenica superior, etc. Since the term phren- ( $\phi \rho \eta v, \phi \rho \varepsilon v)$ has wider connotations - also meaning soul, heart, spirit, or mind - it, in combination with the term skhizein ( $\sigma \chi i \zeta \varepsilon l v$, dividing), forms the well-known clinical term schizophrenia.
The clinical terms mastitis and mastectomia are derived from the term mastos ( $\mu \alpha \sigma \tau o ́$, breast) instead of the term mamma. Similarly, the term thele $(\theta \eta \lambda \eta)$, as the synonym for nipple (papilla mammaria), is present in the names of developmental disorders, e.g. athelia and polythelia, as well as in terms denoting inflammation (theilitis) and plastic surgery of the nipple (theleplastica).

For a student who is only familiar with the term pelvis renalis, the term pyelonephritis fails to fully explicate the inflamed structure. This is because the synonym pyelon or pyelos $(\pi v \varepsilon \lambda o \varsigma)$ is not recognized in the official terminology and most anatomy textbooks. Some clinicians also still use old term for the posterior segmental artery of the kidney (a. segmenti posterioris), based on the term pyelos - a. retropyelica.

Instead of two formal anatomical terms - vesica biliaris and vesica fellea, names of disorders, like cholecystitis and cholelithiasis, or surgical procedures such as cholecystectomia, that involve the gallbladder, contain a third term for the gallbladder - cholecystis or choledochocystis ( $\chi 0 \lambda \eta \delta o ́ \chi 0 \varsigma \kappa v \sigma \tau \iota \varsigma)$. Terms denoting bile: chole $(\chi 0 \lambda \eta)$, bilis and $f e l$ are used in parallel to derive the names of related anatomical structures: ductus choledochus, ampulla biliaropancreatica; vesica biliaris, vesica fellea, while cholecystis contains a part of the phrase denoting the duct of the gallbladder - ductus cysticus. Similarly, the term denoting inflammation of the urinary bladder (cystitis) does not reflect the official anatomical term - vesica urinaria; the terms cystis or kystis ( $\kappa v \sigma \tau \imath \varsigma)$, cystectomia or cystoscopia being instead preferred in clinical settings.

Terminologia Anatomica should include the alternative term for $c o r-c a r d i a(\kappa \alpha \rho \delta i \alpha)$, since it provides the basis for the terms epicardium, myocardium and endocardium, and is often used within the clinical setting, e.g. in cardiology and cardiac arrest. Clinical terms phlebectomia and phlebitis are derived from the Greek synonym for vein - phleps/phlebos ( $\phi \lambda \varepsilon \psi / \phi \lambda \varepsilon \beta o ́ \varsigma)$.

Rare anatomical terms are often used in the names of gastrointestinal disorders. The terms sialoadenitis and sialolithiasis contain the Greek word for saliva - sialon $(\sigma i \alpha \lambda o v)$, instead of Latin term - saliva (which was used in the term glandulae salivariae). The term for inflammation of the lips (cheilitis) omits the official anatomical term labium, but uses rather the Greek cheilos $(\chi \varepsilon \imath \lambda \circ \varsigma)$. Similarly, the term for inflammation affecting mucous membrane of the mouth (stomatitis) is derived from stoma $(\sigma \tau \delta \mu \alpha)$, which could be considered as the proper synonym for the term os. In this way, the term 
stomatology also becomes self-explanatory. Instead of lingua, the term glossa $(\gamma \lambda \omega \sigma \sigma)$ is the basis of the names of disorders affecting the tongue (e.g. glossitis, macroglossia, aglossia) and its associated anatomical structures (e.g. n. glossopharyngeus, $n$. hypoglossus, plica glossoepiglottica).

Gaster and ventriculus should both be used for the stomach, as the case in previous editions of anatomical terminology (International Anatomical Nomenclature Committee, 1966, 1989). This is because both terms are utilized in clinical conditions - e.g. gastritis, and ulcus ventriculi. The term enteron ( $\varepsilon v \tau \varepsilon \rho o v$ ) is used in the name denoting inflammation of the small intestine - enteritis, instead of the anatomical term intestinum tenue; the same term is found in the word gastroenterology. The synonym proctos, for anal canal, is present in the clinical term proctitis and the name of that whole branch of medicine proctology. Greek term for caecum - typhlon enteron is kept in the term typhlitis. Terms omphalocoele, omphalitis, and also ductus omphaloentericus originate from the term omphalos (ó $\mu \phi \phi \alpha \lambda o ́ \varsigma)$ for umbilicus.

In endocrinology, the term glandula adrenalis is used for glandula suprarenalis, e.g. in adrenalectomia, hyper- or hypoadrenocorticismus, as well as adrenalin. Furthermore, term aden ( $\alpha \delta \eta v$ gen. $\alpha \delta \varepsilon v o \varsigma)$ is used more often clinically than glandula, e.g. in the name denoting inflammation of the sweat glands (hydradenitis), inflammation of the lymph nodes (lymphadenitis), in the term denoting the pharyngeal tonsil - adenoids $(\alpha \delta \varepsilon v o \varepsilon \imath \delta \eta \varsigma)$ and its surgical removal - adenoidectomy (Panourias et al., 2012). It should be mentioned that the clinical terms for lymph nodes and tonsils kept with the old view that these are glands; this, however, was subsequently corrected in TA (Panourias et al., 2011).

The term oophoron ( $\omega$ oфópov) should be added to the preferred ovarium, as the case in the examples testis/

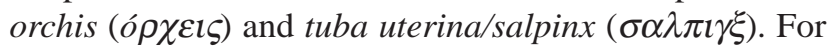
clinical purposes, the term oophoron exists in names like oophoritis and oophoralgia. The terms uterus, hystera $(v \sigma \tau \varepsilon \rho \alpha)$ and metra $(\mu \eta \tau \rho \alpha)$ are used concurrently in the names of different conditions, procedures and medications (e.g. metrorrhagia, hysterectomia and uterotonics). The term metra is also contained in other anatomical terms related to the uterus: endometrium, myometrium, perimetrium. Commonly, ovary and uterine tube are clinically unified by the term adnexa uteri and used in terms like adnexitis and adnexectomia, while being foreign to anatomical terminology. Gynecologists often use the alternative for vagina - colpos ( $\kappa \delta ́ \lambda \pi \% \varsigma$ ), in for example colpitis (used in parallel with vaginitis) or colposcopy; it would therefore appear fully justifiable to include both terms in TA. Moreover, colpos may be the more appropriate term as vagina is also used in the anatomical description of tendon sheaths (vagina, ae - sword-sheath). Without knowledge of the synonym for ductus deferens - vas deferens, (included only as the English variant in Terminologia Anatomica), the term vasectomy (vasectomia) fails, at first sight, to indicate the organ being removed. In similar vein, the clinical terms for penile inflammations - balanitis, posthitis and balanoposthitis, and postectomy - are derived from the Greek terms for glans penis - balanos ( $\beta \alpha \lambda \alpha v o \varsigma)$ and preputium acroposthe $(\alpha \kappa \rho \circ \pi \circ \sigma \theta \eta)$ (Stamatakos).

According to the new anatomical terminology term fibularis is preferred being consistent with the official anatomical term for "adjacent bone" (fibula), but the other name peroneus is kept in the names of corresponding anatomical structures (n. peroneus communis, $m$. peroneus longus, $m$. peroneus brevis; $m$. peroneus tertius). Clinical terminology recognizes the term peroneal palsy is still used; perone ( $\pi \varepsilon \rho o ́ v \eta)$ representing the older, Greek-derived synonym for fibula. The name $m$. omohyoideus is derived from scapula's synonym - omoplata ( $\varpi \mu o \pi \lambda \alpha \tau \alpha \varsigma)$, assigning the bone that gives the attachment of the muscle (Sprumont, 2016). Terms gnathos ( $\gamma \alpha \alpha \theta 0 \varsigma$ ) and genys ( $\gamma \varepsilon v \vee \varsigma)$ for mandible explain terms like gnathology and $m$. genyohyoideus, respectively, while the term ankon ( $\alpha \gamma \kappa \varpi v)$ for cubitus explains the term $m$. anconeus (Schulze \& Donalies, 2008).

The anatomical term cutis is not reflective of the branch of medicine that deals with the skin - dermatology, as this uses the root derma $(\delta \varepsilon \rho \mu \alpha)$. Moreover, derma is found in other anatomical terms, such as dermis and epidermis. Similarly, diseases and conditions such as paronichia or onichomycosis omit the anatomical term

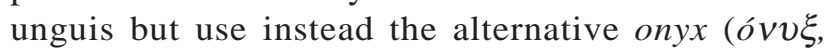

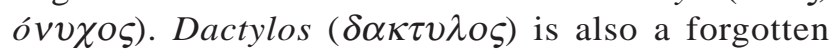
anatomical term denoting finger but can be recognized in clinical terms like polydactyly, macrodactyly, dactylectomy, etc.

The terms suggested in this paper for inclusion in $T A$ eventually (usually at the latter stages of medical education), in one form or another, enter the medical clinical parlance and are adopted by practitioners. It therefore would seem fully justifiable to incorporate them into the official anatomical terminology and to learn them while studying anatomy. This will undoubtedly provide more logic to the learning process and facilitate greater integration with the clinical subjects. 


\section{DISCUSSION}

One of the key components of learning anatomy is mastery of its language. While representing a considerable challenge, this learning is highly rewarding as it enables students not only to understand the content of anatomy, but also that of other pre-clinical and clinical subjects. The aim of this paper is not to criticize official TA but to contribute to this dynamic discourse on terminology and argue that relatively minor changes in $T A$ and/or anatomy textbooks, consisting of the introduction of a number of additional synonyms, could significantly improve the current nomenclature. These changes would be particularly beneficial for students both for the learning of anatomical and medical terminology as well as the integration and alignment of anatomy with the clinical disciplines. Using synonyms may involve some initial increase in learning difficulty and communication (Gobée et al., 2011), but from the broader perspective embodies a more logical approach and therefore the potential to make the studying process ultimately easier and more effective (Smith et al.). Two problems are to be discussed: inconsistencies in the Terminologia itself and inconsistencies between anatomical and clinical terminology.

Like any other language, whether technical or ordinary, the language of anatomy has been continuously evolving, adapting to the constantly shifting landscapes of science and medicine and the needs of their practitioners (Sprumont). This transformation was for a lengthy period of time carried out in a rather haphazard manner, producing diverse usages and terminological confusion. It has been estimated, for instance, that by the end of the nineteenth century anatomists used around 50,000 terms to designate some 5,000 anatomical structures (O’Rahilly, 1989). As medicine, science and society in general, were becoming more "globalized" a need to form universal anatomical terminology and the rules of its application strongly emerged resulting in the production of the nomenclature for the usage across the national boundaries and the confines of different teaching and research traditions. The first step in this process was creation, by a group of renowned German-speaking anatomists, of the compendium of anatomical terms - Basle Nomina Anatomica (Kachlik et al., 2008). Published in 1895, Nomina were not immediately accepted globally. However, in subsequent years through a complex process of discussions and negotiations, a global agreement has been reached on the use of anatomical nomenclature embodied in the latest edition of the $T A$ - a formidable publication containing more than 7,500 terms, produced under the auspices of the International Federation of Association of Anatomists
(Federative International Programme on Anatomical Terminologies, 2011). It comprises Latin anatomical terms (and their English equivalents) originating mainly from the Ancient Greek and Latin, although some terms have their roots in the Sanskrit, Classical Arabic and Ancient Egyptian languages (Polackova, 2001; Wulff, 2004; Sprumont). However, there are many discussions about the content of $T A$ and the validity of using suggested anatomical terms. As noted by several authors, TA still contains some mistakes (Krmpotic-Nemanic \& Vinter, 2003; Kachlik et al., 2009), it is not consistently implemented by anatomists (Vogl, 2009; Martin et al., 2014) and can still be improved and made more user friendly (Bard, 2005; Fabry et al., 2005; Gest et al.), through inclusion of the more recently occurring changes in terminology and rules of nomenclature (Rosse, 2001; Pawlina \& Drake, 2009; Strzelec et al., 2017). There are also internal inconsistencies in $T A$ - different roots are using for naming the homologous structures (i.e. diaphragma and $n$. phrenicus). From the student's point of view it is very important to properly understand the meaning of anatomical terms in order to avoid short-term and mechanical memorization.

The most logical solution would be the introduction of synonyms as was done for tuba uterina, processus articularis (superior/inferior) vertebrae or palatum molle explaining other anatomical terms derived from their synonyms: mesosalpinx, art. zygapophysialis and $m$. levator veli palatini, respectively. Using synonyms may be confusing and problematic in professional communication, like it was suggested by Gobée et al., but it makes studying process easier and effective (Smith et al.).

The inconsistencies of the current anatomical nomenclature with clinical terminology is seen as a further, even greater, problem and impeding medical education (Hirsh et al., 2011; Strzelec et al.). To a considerable degree this is the result of the inconsistencies in clinical terminology as well as the failure of clinicians to use proper terminology (Kachlik et al., 2008, 2009; Strzelec et al.). As Moerkerke \& Ceusters (2000) pointed out it sometimes appears that each clinician has his or her own preferred term. However, although anatomists should not simply dictate to clinicians on how to use the terminology they should perhaps take a more proactive role in connecting it with clinical practice (Martin et al.). Some synonyms in $T A$ help to a large extent understanding relevant clinical conditions (i.e. terms testis and hypophysis correlate with the names of corresponding anatomical structures - $a$. testicularis and fossa hypophysialis, respectively, but their synonyms orchis and glandula pituitaria better correlate 
with the names of corresponding pathological conditions - orchitis and hypopituitarismus, respectively) but some more adjustments in anatomical nomenclature might help narrow the language rift between "the laboratory" and "the clinic". Comparing to previous editions TA (Federative Committee on Anatomical Terminology, 1998) improved some terms and made them more familiar with clinical language (i.e. lien and ren have alternative names - splen and nephros, respectively), but some are diminished (i.e. tractus uvealis). One such relatively small but potentially profitable change would consist in keeping some of the existing terms with the addition of new synonyms like blepharon, pneumon, mastos or proctos. This would not only improve the adoption of other-derived anatomical terms, but also improve their congruency with clinical terminology.

However, while these postulated features, with which undoubtedly most anatomists would agree, appear theoretically sound, in practice they might not be easy to apply. This is particularly the case when they conflict with each other, making terminological solutions more of a set of trade-offs rather than ideal solutions. In a number of cases it might be advantageous to forgo simplicity (i.e. one term for one structure) and introduce synonyms to increase the consistency of nomenclature - both for internal consistency and consistency in relation to other branches of medicine.

This review surely couldn't cover all potential problems in understanding anatomical terminology as well as differences between anatomical and clinical language which gives opportunity for further discussions. Analysis of the origin of rare anatomical terms that are in the clinical use could explain above discussed discrepancies. The history of using those terms is intriguing as well as potential reasons for splitting anatomical and clinical terminology. Sprumont gave an historical overview on the origin of the anatomical terms noticing that "Pathology and Therapy were significantly less Latinized than Anatomy". One of problems while suggesting the potential synonyms for the TA arise from the fact that not all Greek terms have their proper Latin transcription and some survived only in a form of prefixes (e.g. hyper instead of super) (Wulff). Such example is the synonym for the term cornea - term that designates inflammation of cornea (keratitis) originates from the term keras that means horn (lat. cornu) but there is no proper Latin transcription for the cornea itself. Such is the case of term kyklos (lat. cyclos) that is sometimes translated as the ciliary body (Stedman) but actually means "circle" denoting only an association with the ciliary body. Some terms, thus, have to be newly coined.

\section{CONCLUSIONS}

Through the discipline of anatomy and its official nomenclature embodied in $T A$, students also acquire the universal language of medicine. Terminologia Anatomica, however, includes a number of internal and external inconsistencies, which could be easily circumvented by the introduction of relevant synonyms for currently listed terms. Inclusion of these new terms could also be viewed as a transitional stage, since in the future some of the synonyms (those inconsistent with other anatomical and clinical terms) can be eliminated. While the changes suggested here would at first introduce some additional effort on the part of both students and anatomists, this could be a worthwhile trade-off as it would enable better understanding of anatomical and clinical terms and foster deep learning instead of short term, mechanical memorization. Standardization and alignment of anatomical and clinical terms are undoubtedly complex processes. The terminological changes suggested here will not solve all the problems relating to the complexity of anatomical and medical nomenclature, but might be a step in pointing anatomy, medicine and medical education in the right direction, i.e. towards improved comprehension of medical concepts among medical students and better communication between practitioners.

GALIC, B. S.; BABOVIC, S. S.; VUKADINOVIC, S. \& STRKALJ, G. Relevancia clínica de la terminología anatómica oficial: La importancia de usar sinónimos. Int. J. Morphol., 36(4):11681174, 2018.

RESUMEN: Terminologia Anatomica es una colección única de términos técnicos que permiten la comunicación en anatomía y medicina en todo el mundo. Sin embargo, la terminología anatómica actual también contiene algunas inconsistencias internas y discrepancias con respecto a la terminología clínica. Por lo tanto, varios términos no están lógicamente relacionados con los nombres de entidades anatómicas similares, o los nombres de las correspondientes condiciones fisiológicas y patológicas. Además, durante la práctica clínica muchos términos anatómicos han sido comúnmente reemplazados por nuevos modismos clínicos. Estas discrepancias terminológicas representan un impedimento para el aprendizaje y la enseñanza en los programas médicos y profesionales de la salud. En este trabajo se propone que los sinónimos relevantes se introduzcan en la terminología anatómica de la misma manera que en la actualidad, como en el caso del riñón (ren / nephros) y la tuba uterina (tuba uterina / salpinx). Este cambio reduciría significativamente las inconsistencias en la nomenclatura y haría la terminología anatómica más lógica, más fácil de entender y memorizar. Además, alinearía mejor la anatomía con otras áreas de la medicina y la educación médica.

PALABRAS CLAVE: Nomenclatura anatómica; Terminologia Anatomica; Educación en anatomía; Educación médica; Sinónimos. 


\section{REFERENCES}

Bard, J. B. Anatomics: the intersection of anatomy and bioinformatics. $J$. Anat., 206(1):1-16, 2005.

Fabry, P.; Baud, R. \& Lovis, C. Towards a multilingual version of Terminologia Anatomica. Stud. Health Technol. Inform., 116:665-70, 2005.

Federative Committee on Anatomical Terminology (FCAT). Terminologia Anatomica. International Anatomical Terminology. Stuttgart, Thieme, 1998. pp.292.

Federative International Programme on Anatomical Terminologies (FIPAT). Terminologia Anatomica. International Anatomical Terminology. $2^{\text {nd }}$ ed. Stuttgart, Thieme, 2011. pp.292.

Federative International Programme on Anatomical Terminologies (FIPAT). Terminologia Neuroanatomica. FIPAT.library.dal.ca. Federative International Programme for Anatomical Terminology, 2017.

Gest, T. R.; Burkel, W. E. \& Cortright, G. W. A need for logical and consistent anatomical nomenclature for cutaneous nerves of the limbs. Anat. Sci. Educ., 2(3):126-34, 2009

Gobée, O. P.; Jansma, D. \& DeRuiter, M. C. AnatomicalTerms.info: heading for an online solution to the anatomical synonym problem hurdles in data-reuse from the Terminologia Anatomica and the foundational model of anatomy and potentials for future development. Clin. Anat., 24(7):817-30, 2011.

Hirsch, B. E. Does the Terminologia Anatomica really matter? Clin. Anat., 24(4):503-4, 2011.

International Anatomical Nomenclature Committee (IANC). Nomina Anatomica. $3^{\text {rd }}$ ed. Amsterdam, Excerpta Medica Foundation, 1966. pp.112.

International Anatomical Nomenclature Committee (IANC). Nomina Anatomica. $6^{\text {th }}$ ed. Edinburgh, Churchill Livingstone, 1989. pp.E52.

Kachlik, D.; Baca, V.; Bozdechova, I.; Cech, P. \& Musil, V. Anatomical terminology and nomenclature: past, present and highlights. Surg. Radiol. Anat., 30(6):459-66, 2008.

Kachlik, D.; Bozdechova, I.; Cech, P.; Musil, V. \& Baca, V. Mistakes in the usage of anatomical terminology in clinical practice. Biomed. Pap. Med. Fac. Univ. Palacky Olomouc Czech Repub., 153(2):157-62, 2009.

Krmpotic-Nemanic, J. \& Vinter, I. Incorrect medical terms in Terminologia Anatomica (1998). Ann. Anat., 185(2):195-6, 2003.

Martin, B. D.; Thorpe, D.; DeLuna, V.; Howard, T.; Hagemeyer, J. \& Wilkins, N. Frequency in usage of Terminologia Anatomica terms by clinical anatomists. J. Biomed. Educ., 2014:950898, 2014.

Moerkerke, C. \& Ceusters, W. The Myth of Preferred Terms In Medical Sublanguage And Its Impact on Natural Language Understanding Applications: An Empirical Study. In: De Moor, G. \& De Clercq, E. (Eds.). Proceedings of the 18th MIC Conference, 2000. pp.55-62.

Mosby’s Medical Dictionary. St. Louis, Mosby Elsevier, 2013.

O’Rahilly, R. Anatomical terminology, then and now. Acta Anat. (Basel), 134(4):291-300, 1989.

Panourias, I. G.; Stranjalis, G.; Stavrinou, L. \& Sakas, D. E. The ancient Hellenic and Hippocratic origins of head and brain terminology. Clin. Anat., 25(5):548-58, 2012.

Panourias, I. G.; Stranjalis, G.; Stavrinou, L. C. \& Sakas, D. E. The Hellenic and Hippocratic origins of the spinal terminology. J. Hist. Neurosci., 20:177-87, 2011.

Pawlina, W. \& Drake, R. Moving forward with Terminologia Anatomica. Anat. Sci. Educ., 2(3):93, 2009.

Polackova, G. Synonymy of medical terminology from the point of view of comparative linguistics. Bratisl. Lek. Listy, 102(3):174-7, 2001.

Rosse, C. Terminologia Anatomica: considered from the perspective of nextgeneration knowledge sources. Clin. Anat., 14(2):120-33, 2001.

Schulze, P. \& Donalies, C. Anatomisches Wörterbuch. Lateinisch-Deutsch/ Deutsch-Lateinisch. 8. Aufl. Stuttgart, Thieme, 2008.

Smith, S. B.; Carmichael, S. W.; Pawlina, W. \& Spinner, R. J. Latin and Greek in gross anatomy. Clin. Anat., 20(3):332-7, 2007.
Sprumont, P. Anatomical terms: towards development of Terminologies (terminogenesis). Eur. J. Anat., 20(3);249-80, 2016.

Stamatakos, I. Dictionary of the Ancient Greek language. Phoenix, Athens, 1972.

Stedman, T. L. Stedman's Medical Dictionary for the Health Professions and Nursing. Philadelphia, Lippincott Williams \& Wilkins, 2005.

Strzelec, B.; Chmielewski, P. P. \& Gworys, B. The Terminologia Anatomica matters: examples from didactic, scientific, and clinical practice. Folia Morphol., (Warsz), 76(3):340-7, 2017.

Vogl, A. W. Awareness of and access to a unified terminology by anatomists. Anat. Sci. Educ., 2:139-40, 2009.

Wulff, H. R. The language of medicine. J. R. Soc. Med., 97(4):187-8, 2004.

Corresponding author:

Prof. Dr. Biljana Srdic Galic

University of Novi Sad

Faculty of Medicine

Department of Anatomy

Hajduk Veljkova 3

21000 Novi Sad

SERBIA

\section{Email: biljana.srdic-galic@mf.uns.ac.rs biljana.srdic@uns.ac.rs}

Received: 18-06-2018

Accepted: 22-08-2018 